\title{
From high waters forecasts to flooded areas forecasts
}

\author{
Aurélie Escudier ${ }^{1, a}$, Pierre-Adrien Hans ${ }^{2}$, Christophe Astier ${ }^{1}$ and Jean-Luc Souldadié ${ }^{1}$ \\ ${ }^{1}$ Ministry of Ecology, Sustainable Development and Energy, French National Flood Forecasting Service (SCHAPI), 42 avenue Coriolis, \\ 31057 Toulouse Cedex 1, France \\ ${ }^{2}$ DREAL Centre Val de Loire, FFC LCI-5, Avenue Buffon, BP 6407, 45064 ORLEANS Cedex 2, France
}

\begin{abstract}
Flooded areas are key information to crisis managers, both at local and national level. They help sizing human and material resources to be deployed before and during a flood. These data already exist on several French rivers as they are been produced in a legislative framework but mainly addressing the hundred-year flood. The purpose of the Flood Forecasting Services is to complete water levels forecasting published on www.vigicrues.gouv.fr with forecasting information on spatial flooded areas. State services are developing new flooded areas ranging from first overflows to the hundred-year floods. A national database called VIGInond provides secure web services to access these new data. It was developed in 2015. A key step in the standardization of these new data is the collaboration between various state services. The access to VIGInond is initially opened to the Ministry of Interior services. This first step allows the operators to test and to understand the impacts of forthcoming flooding. Once tested, it will be made available to other crisis managers through the forthcoming Vigicrues ${ }^{\circledR}$ portal version 2. The new data will be gradually included in Vigicrues ${ }^{\circledR}$ watercourses, while coastal areas and new watercourses will be subsequently added. These new information will increase awareness of flooding risks among stakeholders and citizens in the near future.
\end{abstract}

\footnotetext{
a aurelie.escudier@developpement-durable.gouv.fr
} 


\section{Foreword and objectives}

The French National Flood Forecasting Service (called SCHAPI as Service Central d'Hydrométéorologie et d'Appui à la Prévision des Inondations), head of the 19 Flood Forecasting Centres (FFC), broadcasts twice a day the hydrological vigilance on a dedicated website www.vigicrues.gouv.fr. This flood vigilance is illustrated by four color levels (green, yellow, orange or red) on 286 sections of 232 rivers, about $22000 \mathrm{~km}$ long. The hydrological conditions of these sections, called linear or monitored [by the State] network, is surveyed by the 19 Flood Forecasting Centres (FFC). From the vigilance of yellow level on at least one of their river sections, FFC write a bulletin with appropriate forecasts of water levels and / or discharge. These forecasts are calculated at the hydrometric stations identified as "forecast points".

The challenge, not only for crisis managers and the authorities (government services, emergency services, mayors, etc.) but also for the citizen is to combine the forecast at a given point - a water level at a gauging station - to a spatialized hazard - a flooded area.The difficulty is therefore to determine the consequences on the field at the scale of the area :

- what will be the affected assets for the forecasted height at the station?

- $\quad$ where I live and will my activities be impacted?

Various actions provide answers to these questions: pre-positioning of response capacities, evacuation of vulnerable facilities, establishment of collective and individual actions.

Out of the countries developing national flood forecasting systems, only several of them are providing information on flooded areas. The Australian Government established the National Flood Risk Information Project (NFRIP). The project aims to improve the quality, availability and accessibility of flood information across Australia, and raises community awareness of flood risks. NFRIP is committed to delivering a number of significant outputs, including the development of an online portal (http://www.ga.gov.au/flood-study-web/) to provide a single point of access to existing flood risk information. Only historical and localized information are provided, very few spatial data are available. In the USA, DATABASE is to gather and unify information about flash flooding from different sources and detailed spatial investigations [1]. This project is dedicated to the gathering of observed flooded areas and their visualization on the application.

In France, the FFC and SCHAPI have the goal to gradually provide information on forecasted flooded areas along the monitored network. This national project is developed in response to crisis managers who need information on potential flooded areas corresponding to a forecasted level at a gauging station. SCHAPI is therefore providing a robust and operational system.
The project is integrating :

- the production of several expertized scenarios for flooded areas by the FFC, each scenario being linked to a specific water level at the gauging station;

- the development of a database to store and manage flooded areas dataset at national level, as well as import features on a unique environment, called VIGInond ;

- the establishment of interoperable data flow and tools for dissemination in order to easily provide VIGInond data.

The produced VIGInond dataset can be used in two contexts:

- preparation of flood crisis by sharing and appropriating the content of such data between crisis managers;

- management of the crisis for the areas where operational data sets can be used to better anticipate the flooding based on the forecast.

\section{A new reference framework of flooded areas}

\subsection{From a land-use planning cartography to a cartography for crises management}

Flood risk cartographies have been produced for several years in France [2], especially through the preparation of atlases of flooded zones. Another example is the elaboration of the flood risk prevention plans since 1995. These data are used in land-use planning when regulating the soil use, the way of building and the use and management of the flood risk areas in a global risk approach.

During crisis management, these data are usually unexploited for two reasons: on one hand, because there is generally no link between these maps and an ongoing flood, on the other hand, because the data currently produced do not give any information on the floods which are more frequent than the 100-year flood.

The information provided by SCHAPI on the Vigicrues ${ }^{\circledR}$ website is a forecast at a specific point by the hydrometric station for an ongoing event. The difficulty for the crisis managers lies in associating this forecast at a given point $-\mathrm{a}$ height at a station - to the predictable consequences on the ground at a given territory level. This difficulty can be solved by using a new reference framework for flooded areas : the potential flooded areas (ZIP for Zone d'Inondation Potentielle).

Linking every ZIP together with a water level at a hydrometric station of the national reference framework is the key point, and this criteria is the basis of the produced information (Fig. 1 below).

In some particular cases, ZIP can be linked to several hydrometric stations, especially in the confluence or estuarine areas, where the extent of the flooded areas can depend on the different contributions of the tributaries or be influenced by the tide or a by a sea-level higher than 
expected because of meteorological phenomena, such as storm surge.

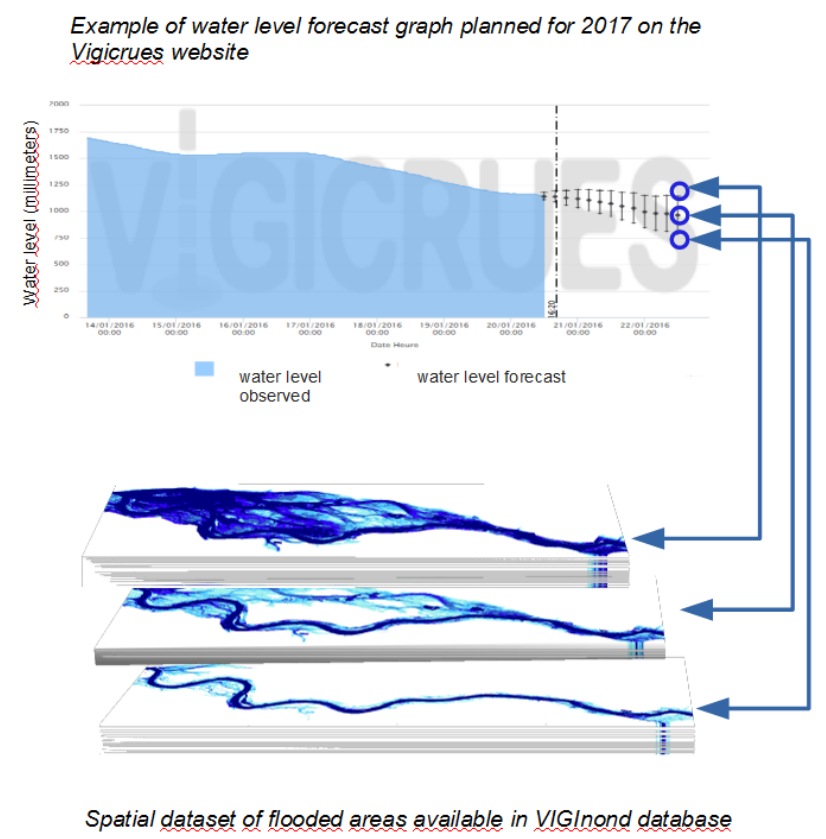

Figure 1. Link between 3 forecasted water levels at a gauging station and their corresponding scenarios of flooded areas

\subsection{A relationship to translate the level at a gauging station into a flooded area}

\subsubsection{Critically assessed cartography rather than real-time cartography}

To prepare crisis, using pre-established scenarios, combined with a support and an adapted awareness of the actors, remains essential for the characterization of the impacted vulnerable issues. For crisis management, two approaches can be studied :

- using pre-established scenarios which can be more or less similar to the ongoing flood, being well aware that each flood has not exactly the same dynamics than another one (levels, volumes, contributions of the tributaries, etc.).

- using real-time cartography of the ongoing flood, assuming that the actors have the relevant tools for real-time data visualization.

Between 2009 and 2010, the feasibility of using a real time forecast of flooded area was tested out by the FFC responsible for the Oise-Aisne watersheds [3]. This experiment was based on a virtual flood episode, using the modelling platform of the FFC, which integrates hydrologic and hydraulic modules, as well as a cartographic module, which had been adapted and improved for the test.

The experiment showed that real-time cartography requires an operational and fast series of calculations including at least three prerequisites:

- a real-time forecasting model under the form of a hydrodynamic model for the watercourse,

- a model delivering flood results in short terms and in accordance with the production of the FFCs (a few minutes)

- tools to easily process and quickly represent the results of the model in order to carry out the cartography of the flooded areas.

Beyond the technical aspect, another question was raised: could the lack of critical assessment of the cartographic productions be prejudicial?

Considering this issue and such prerequisites, it was decided in 2011 that the flooding forecasting would be based on a series of ZIP in a first approach. During floods, the work implies to refer to this list and to propose the flooding scenarios as close as possible to the ongoing flood, choosing a low (or minoring) scenario and a high (or majoring) scenario.

\subsubsection{A spatial and temporal extension to specify}

The choice to produce static cartographies implies the following question: how to minimize the role of the different dynamics of various floods in order to obtain a relevant cartography?

The relationship between the water level at a gauging station and the consequently flooded area is linked to the issue of "influence zone". The influence zone corresponds to the watercourse length on which the flooding phenomenon is directly correlated to the station level. This means that the variability of the flood extent is minimal in influence zone of a station and for a given level at this station. In a first approximation, the influence zone of a station can be defined by the watercourse length around this station between two major confluences. However, some phenomena reduce this correlated length, and end up in " white areas " where the variability of the flooded area for a given level at the station becomes noteworthy.

The extent of the flooded area compared to a given level $\mathrm{H}_{0}$ at a station can be defined in several ways : (i) in an instantaneous way, in which we focus on the flooded area state at time $\mathrm{t}$, when $\mathrm{H}_{\text {station }}(\mathrm{t})=\mathrm{H}_{0}$; (ii) according to the maximum extent, in which we focus on the maximum flooded area resulting from a maximum level at the station $H_{\max }=\max \quad t \in$ flood $\left\{H_{\text {station }}(t)\right\}=H_{0}$. The first option allows drawing a pseudo-real time cartography, but it requires real-time data on the whole river section, which is only feasible with an hydrodynamic model. Furthermore, the use of past floods data only allows reconstructing the maximum flood state. Thus, the static maps must represent the flooded area corresponding to the maximum level $\mathrm{H}_{\max }$ reached at a station.

\subsection{A national database to store three types of information}

VIGInond - the national database of flooded areas was developed under the contracting authority of SCHAPI and transferred to the FFC in February 2015. It stores the cartographic layers of the flooded areas in a specific format.

Three types of geographical information can be stored in the database (see Fig.2) : 
- the ZIP area representing the extent of the flooded surface for a water level at the hydrometric gauging station as representative as possible for the related sector. It is characterized by its outline and its upstream and downstream limits which best delimit the influence zone around the hydrometric station(s).

- the areas flooded for a number of Water Height Classes for each ZIP: they represent the submersion heights related to the natural ground level.

- the Iso Elevation Lines for each ZIP : these lines are the maximum iso-elevation curves reached by water during a flooding in a unique levelling system datum (NGF IGN69).

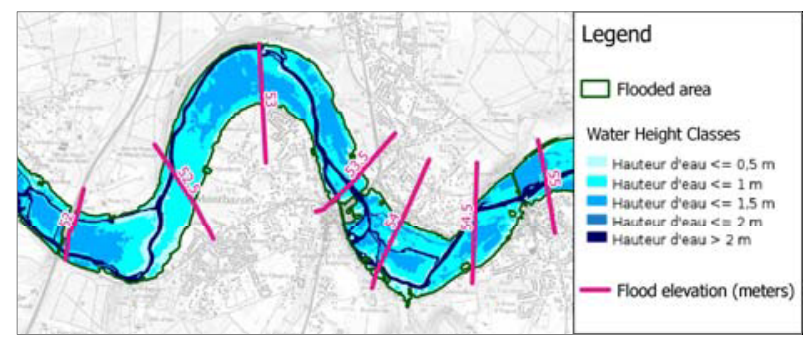

Figure 2. Three types of geographical information stored in the database and produced at Cormery station (37) on Indre river (C) DREAL Centre Val de Loire - IGN $\operatorname{scan} 25()$

All the information stored in VIGInond is in vector format, in order to be interoperable with other information, especially with the layers describing vulnerable assets which are used by the crisis managers.

\section{Flooded area development}

\subsection{Prerequisites for flooded area mapping on monitored rivers}

Between 2008 and 2011, FFC and SCHAPI performed preliminary works on flood mapping in order to define if prerequisites were needed before engaging flooded area mapping at a national level.

Since 2011, several methods of data acquisitions have been nationally implemented. They complement those already used by the FFC and other State services involved in flood risk, improving therefore the pooling of the FFC experience in data acquisitions.

Thereby, two types of prerequisites have been identified: those concerning flood hazard and those related to topography.

\subsubsection{Consolidation of knowledge and data gathering on flood hazard}

In order to ease the representation of observed floods, field work must identify the highest water level reached during the flood. These marks allow comparison with past and future events.

One important task consists in pooling funding to purchase aerial and satellite photography. In 2013, the establishment of an agreement between the French national geographical institute (IGN) and General Directorate of Risk Prevention (DGPR) was signed to obtain ortho-rectified data and to perform data mosaicking during a flood. The agreement includes not only data acquisition and processing but also the development of a methodology to establish a GIS layer of observed flooded areas. This is the first partnership on this issue between a national agency and the Ministry. Airplanes used to take measurements in good meteorological situation have been called up for new mission types.

Between 2013 and 2015, fifteen aerial missions have been launched on major floods. They allowed:

- reporting the necessary reactivity from IGN $(6 \mathrm{~h}$ to $12 \mathrm{~h}$ between activation and actual measurement campaigns). Indeed, the need to obtain data during the highest flood level calls for responsiveness.

- $\quad$ targeting the most suitable products for the FFC and for mapping the observed flooded areas. Vertical and geo-referenced images obtained at low altitude with high resolution sensors led to high quality data (raw images with a resolution mostly under $20 \mathrm{~cm}$ ).

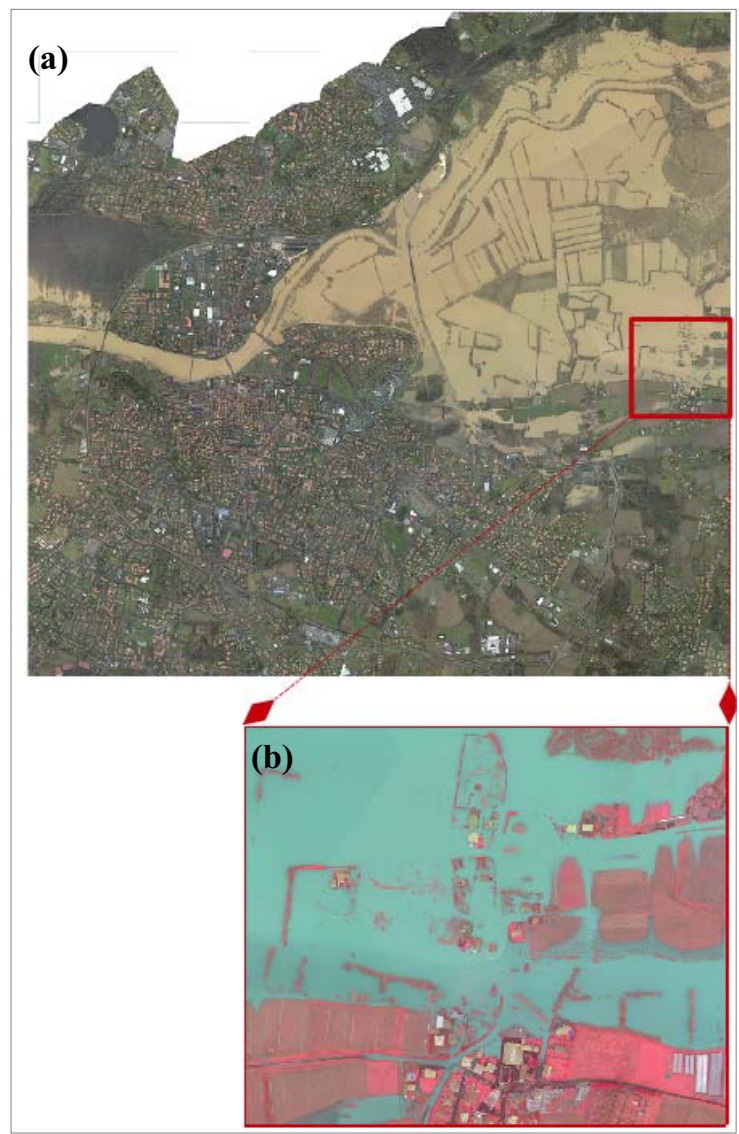

Figure 3. OrthoExpress images obtained on Adour river in January 2014 - (a) OrthoExpress Color (b) OrthoExpress InfraRed Color

Pre-treatments applied on the images are similar to those used in a new IGN product : OrthoExpress (see Fig. 3 above). In order to minimize the delay, data results 
from a highly automated processing, therefore saving delivery time, and gaining costs as well. Now, OrthoExpress perfectly meets photo-interpretation needs of the FFC.

Since 2013, several satellite missions were also conducted in the framework of the End-User Thematic Part of the ORFEO Accompaniment Program. This new high resolution information were tested during a project for rapid cartography within a partnership between CNES (the Spatial Agency), SCHAPI and SERTIT (the technology transfer Center for Earth Observation data of the University of Strasbourg [4]. The results show that the satellite system is sufficiently agile and that the obtained data match the needs of crises managers.

Besides pooling the aerial datasets at national level, a methodological guide has been produced by the services of the Environment Ministry. It describes a protocol for assisting services on collecting highest water levels after a flood, as well as technical and organizational aspects. A tender template completes the guide, in order to launch very quickly a consultation for field work just after a flood event.

Finally, the current development of a national repository for floods marks will allow data consolidation to improve the knowledge and use of former flood lines [5].

\subsubsection{Precise topographic data}

\section{- Levelling gauge datum of hydrometric stations}

On the Vigicrues ${ }^{\circledR}$ website, changes in the water level (Hwater) at stations are mostly plotted relatively to the gauge datum ( 3 in the scale $=3 \mathrm{~m}$ from its zero).

In order to translate the water level measured at a gauge in water level (Zwater) in an absolute coordinate system (here IGN $69 \mathrm{NGF),} \mathrm{the} \mathrm{gauge} \mathrm{altitude} \mathrm{(Z0)} \mathrm{must}$ be precisely measured.

\section{Zwater $=Z 0+H w a t e r$}

With Zwater value, it is easy to compare the water level can be compared to the natural ground elevation to determine if the area is flooded or not. A public contract across France conducted to level nearly 500 gauge datum among 1600 stations on Vigicrues ${ }^{\circledR}$.

\section{- $\quad$ Fine topographic data - LIDAR Digital Terrain Model (DTM)}

As part of the Flood Directive [4], a high resolution DTM acquisition program by LIDAR Technology was conducted between 2011 and 2014. These topographic data cover floodplains on about $80 \%$ of the linear river sections surveyed by hydrological vigilance, providing therefore an essential database for the mapping of future flooded area (see DTM comparison on Fig. 4 after).

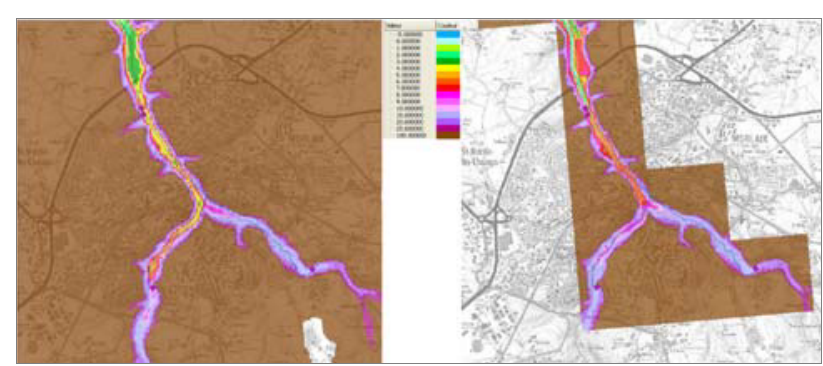

Figure 4. Comparison of BDAlti ${ }^{\circledR}(25 \mathrm{~m}$ resolution $)$ and LIDAR DTM ( $1 \mathrm{~m}$ resolution) on Morlaix river.

\subsection{Support for the production of potential flooded zone}

\subsubsection{A new organization is needed between producers}

Collection of data on existing flooded areas is an important step toward the consolidation of a dataset for the VIGInond database. Collaborative work must be organized between State services and other partners, such as public establishments and basin communities (See Fig. 5 below).

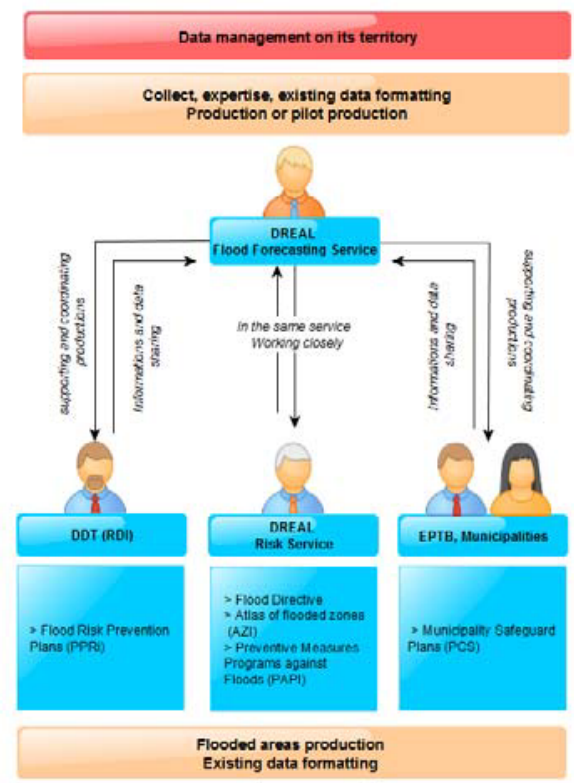

Figure 5. Organization between data producers on flooded areas

The FFC is the central point of this work, as pilot or co-pilot, because the hydrologist are able to analyze the existing scenarios and can help choosing additional scenarios. This type of expertise is mandatory to control the hydraulic consistency between the flooded area and the water height forecasts which are calculated at the station by the FFC.

Several services are identified to provide support on production and consolidation of flood areas on the Vigicrues ${ }^{\circledR}$ river network: Departmental Directorates for Territories and Sea through the mission of Department Flood Adviser and during the preparation of flood risk prevention plans. Thereby, Departmental Directorates are 
used to ask for additional hydrological scenarios during the studies for flood risk prevention plans:

- Regional Directorates of Environment follow the fulfilment of the three Flood Directive scenarios;

- Public and Territorial River Basin Institutions, as cooperative public institutions funded by local authorities, participate into special programs, on Preventive Measures against Floods and Water Management and Developing Scheme, for which hydraulic studies may be initiated;

- Municipalities within the framework of Municipal Safeguard Plans or Special Intervention Plan;

- $\quad$ any qualified structure.

\subsubsection{A national leadership}

SCHAPI, as French National Flood Forecasting Service, is part of Environment Ministry and has been appointed to lead the consolidation of these new datasets.

By encouraging a national approach for the forecasting of flooded areas, SCHAPI became responsible for the organization of the data collection on potential flooded area. This task includes also the coordination of any local actions related to the implementation and the broadcasting of this new reference data.

The Floods Directive has led to the development of several tools based on open source software in order to meet the requirements for an industrial production of data on flooded areas. The use of high resolution DTM LIDAR topographic data raised questions about their use and the weight given to data during processing. Tools, such as Cartino [6] developed by CEREMA (Center for Studies and expertise on the risks, the environment, mobility and planning) or Cartalin developed by the Rhône-Alpes regional service of the Ministry of Environment helped initiate answers about the resampling of DTM LIDAR and the reduction of output data [7].

Based on these early experiences, SCHAPI and the FFC initiated a tool to meet the specific requirements of flood forecasting : CartoZI, developed on Open Source GIS software - QGIS - has been porting at a national level. CartoZI offers to the users a series of modules especially developed to take account of hydraulic and topographical data into the definition of flood zones. The method underlying the tool are the basic principles of flood mapping :

- Step 1: Establish the profile along the water surface based on 3 different methods:

reconstitution of the water surface for an observed event, by using all available historic data for this event : flood marks or water marks, aerial photographs or satellite images from the flooded area;

linear interpolation of water surface from existing records ;

calculation of a water surface with a 1D model.
Each water surface is given in height units (in NGF meters). For the calculation of potential flooded area (ZIP), this water level is translated into relative height to the reference hydrometric station datum. When a model is available, the rating curve is used to calculate the water surface from the discharge $(\mathrm{m} 3 / \mathrm{s})$ at the hydrometric station.

- Step 2: Create the digital model of the free water surface by horizontally projecting the water surface along the river profile (on the right and left bank), in order to build the related numerical model.

- Step 3: Calculate the digital model of water heights by subtracting the natural field elevation to the water surface. Subtracting the elevation of natural terrain to the level of the modeled water surface then provides the difference of these two digital models. Negative values correspond to areas outside of flooding, while positive values correspond to water heights located within the flooded zone defined by the model.

Using accurate DTM LIDAR allowed to demontrate that smoothing algorithms need to be improved. The added value of CartoZI, next to its simple use, is that its results smoothing module allows to reduce the weight of the data, while keeping the accuracy of information. This exercise helps to gain clarity by decreasing artifacts and false impression of precision. Smoothing is available in 2 methods in the module:

- removal of small polygons that we judge not representative: depending on the scale of intended use, maintain lower polygons to a certain area is not helpful (for example, at $1 / 25000$ scale, $500 \mathrm{~m}^{2}$ surface corresponds to a 1 $\mathrm{mm}^{2}$ surface on the paper version);

- changing the geometry: the disadvantage of working from a raster is that the resulting layer is "angular"; in addition to be hardly viewing, and this increases the file size. This optional process changes the contours to mitigate these effects.

Two types of smoothing can be applied:

- the raster smoothing. The idea is to use a neighbor pixel to assign values. This neighborhood and its attributed weighting are defined by a matrix filter. For each pixel, the module performs a weighted average of neighboring pixels, and assigns the new value to the central pixel.

- the vector smoothing gives the possibility to use two geometric algorithms:

a Chaikin algorithm [8]. Chaikin's method proceeds as follows: given a control polygon, we refine this control polygon by generating a new sequence of control points ;

a Ramer-Douglas-Peucker algorithm (See Fig. 6 below). The principle is to begin from a line of $\mathrm{n}$ nodes and progressively to remove intermediate nodes if the distance between each node and the simplified line 
is smaller than the tolerance set by the user.

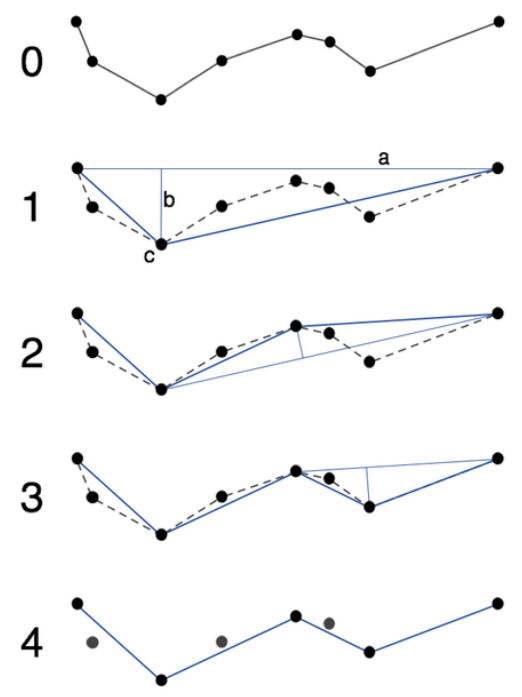

Figure 6. Ramer-Douglas-Peucker algorithm - The original uploader was Leupold at German Wikipedia [CC BY-SA 2.0 de (http://creativecommons.org/licenses/by-sa/2.0/de/deed.en)], via Wikimedia Commons

It is possible to combine several times the couple "Chaiken - Ramer-Douglas-Peucker" to increase smoothness. The use of smoothing module reduces up to 10 times the size of the data (see Fig. 7 below):

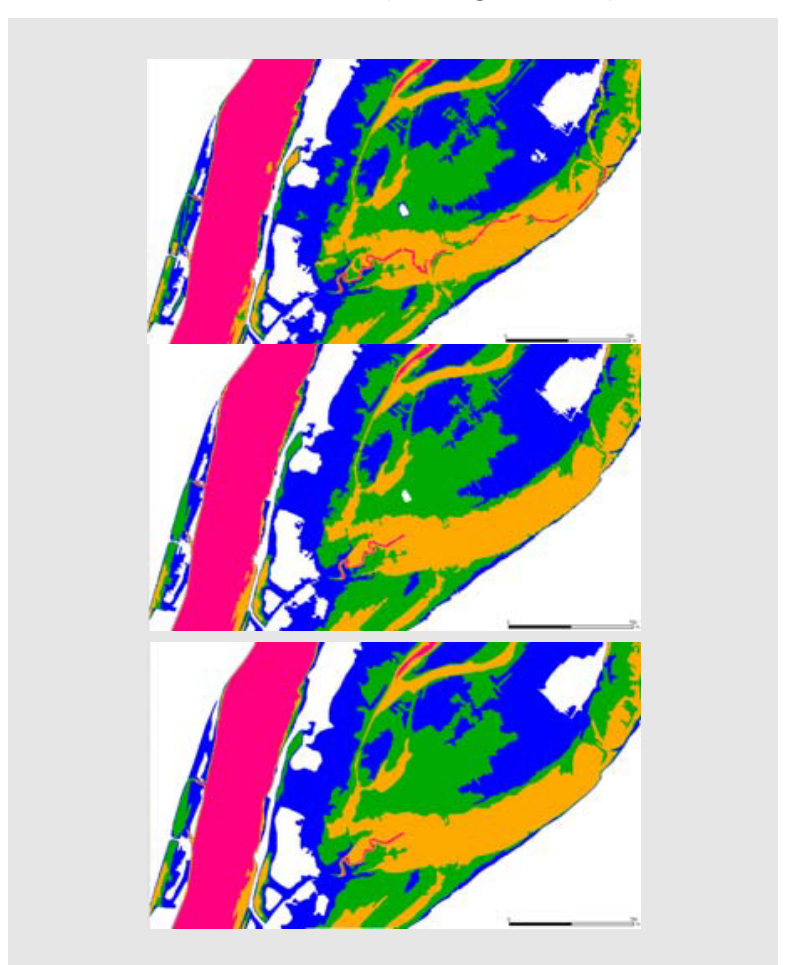

Figure 7. Example of smoothing module use in CartoZI

CartoZI is planned to be distributed to data producers, but only to services on the ministry network for the first half of 2016.

\subsection{Prioritizing productions}

\subsubsection{Valuing knowledge from the Floods Directive}

The Floods Directive helped initiating significant mapping of flooding area for the most vulnerable territories in France and Overseas. 122 Territories of Significant Risks of flooding (TSR) have been defined. Out of the approximately 7700 municipalities covered and warned by the Vigicrues ${ }^{\circledR}$ system, nearly 1,600 are located inside of a TSR (see Fig. 8 before).

Therefore, these areas are covered by 2 or 3 flood maps created for the Floods Directive, including frequent and medium scenarios. These scenarios form a first dataset that can be integrated into VIGInond.

Before VIGInond import, a data recover is needed. First, an analysis is required to link Floods Directive scenario to a water height at a hydrometric station, preferably located within a TRI. Definition of influence zones and VIGInond standard compliant data formatting needs also to be done.

Moreover, hydraulic models have mostly been built or reused to produce all or part of three scenarios of the Flood Directive. Using these models on a few extra flood scenarios will be possible if these models are well calibrated. In a challenging public economy, the cost to carry this additional work on TRI will be weighed against the gains for the community in matters of:

- rescue team mobilization and flood damage reduction;

- crisis preparation and preventive action improvement.

\subsubsection{Progressive increase of monitored network coverage}

A first work has been achieved to identify the municipalities with a significant population impacted by a flooding risk. This task allowed identifying areas for which mapping efforts must be made in upcoming years.

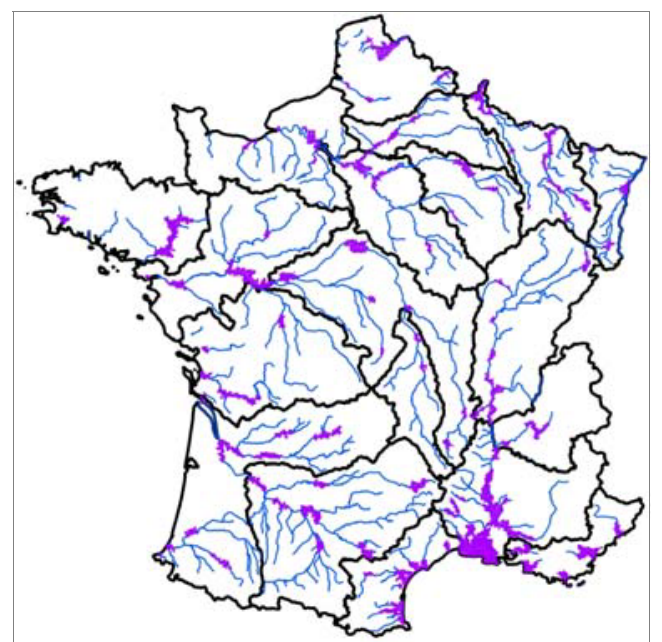

Figure 8. Municipalities informed by Vigicrues ${ }^{\circledR}$ and included in a Territory of Significant Risks of flooding (TRI) 
We can stress that the 1600 municipalities informed by Vigicrues ${ }^{\circledR}$ and included in a TRI gather $77 \%$ of residents in flood-prone areas, while they only represent $20 \%$ of Vigicrues ${ }^{\circledR}$ network (according to the ratio Pareto principle).

An analysis based on data from the first phase of the Flood Directive highlighted that cities outside TRI are in flood zones for an extreme event:

A 13 towns with more than 10000 inhabitants;

A 54 towns with more than 5000 inhabitants;

A 533 cities with more than 1000 inhabitants.

Adding these towns to the ones included in a TRI "Vigicrues ${ }^{\circledR}$ ", leads to a total of 25 to $30 \%$ of Vigicrues ${ }^{\circledR}$ network, standing for $90 \%$ of inhabitation and population in flood zones.

These areas must be targeted in priority for flood mapping in upcoming years.

\section{Dissemination of the produced data}

\subsection{Sharing of information for the preparation and crisis management}

\subsubsection{Tools for data visualization}

Since March 2016, VIGInond data are made available to a first group of crisis management actors, risk services in Regional Directorates of Environment and the FFC, by providing alphanumeric and cartographic web services.

Web services make database interoperable with other databases and visualization tools. These web services are operated by applications of the Ministries in charge of Environment and Interior, allowing therefore visualization of flooded areas with different levels of expertise and uses :

- a dedicated application and accessible through the government portal Georisques (see Fig.9 after) on its "Internal" part reserved for state services with a secured extranet. This platform aims to view relatively simply and intuitively flooded areas of data with other geo-referenced data associated to risk.

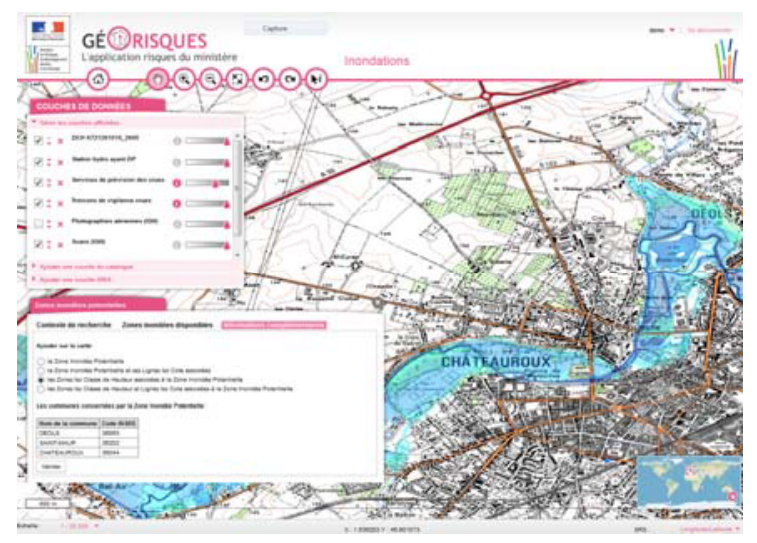

Figure 9. A flooded area visualization on Géorisques government portal (with scan $25 \AA$ - IGN)
- a software application on QGIS "VIGInond INVITE" (see Fig. 10 below) developed by the FFC Loire-Cher-Indre and for specialists in geomatics, who wish to cross these expert data with their own other geographic layers (including specific issues).

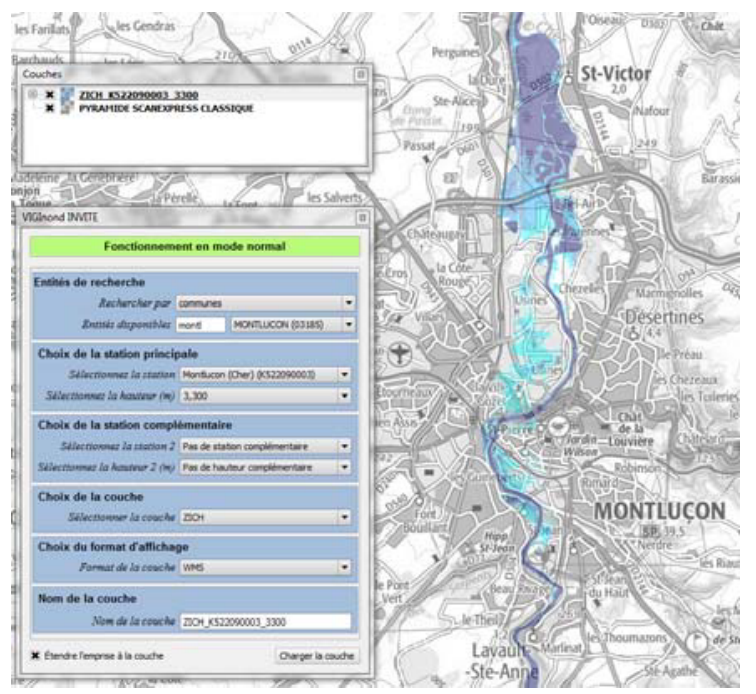

Figure 10. A flooded area visualization on VIGInond INVITE application (with scan25® - IGN)

\subsubsection{The exploitation of flooded areas by crisis managers}

For crisis management or for the FFC themselves on the part of the network where they have not experienced significant flood, the determination of the impacted flooded area from the only information of observed and/or forecasted water level or discharge provided at a hydrometric station is a difficult exercise. Therefore, advices for behavior to be followed, the measures of resources and evacuations are still difficult to determine.

The use of VIGInond's visualization and interrogation tools has the first objective of a common understanding of the hazard, thus improving knowledge of the issues affected by flooding, either by crossing with specific geographic strata or simply by viewing a map background, during the preparation phase and crisis management.

This objective is to help consolidate the relationship between the FFC and the mission of Department Flood Adviser on flooded areas produced data. On one hand, these exchanges are the basis for a continuous improvement of hazard data, including criticizing the hazard area mapped after each event compared to the actual flood zone, but also the improvement of vigilance levels by characterizing the corresponding impacted vulnerabilities. Furthermore, they must enable to aware the crisis management actors of the relationship between the observed, or expected, water level at a hydrometric station on Vigicrues ${ }^{\circledR}$ and the corresponding flooded area.

Finally, the dissemination to Department Flood Adviser and the prefectures of these data on flooded areas should allow them to provide the best support to 
communities in defining Municipality Safeguard plans, as well as the most appropriate protective measures depending on the observed, or forecasted, water level at the nearest gauging station or the most relevant for the concerned municipalities. To know the areas that will be flooded, allows also determining the areas which are not going to be flooded.

\subsection{A gradual dissemination for a better understanding of the impacted areas.}

The dissemination of this information to the general public is still subject to major exchanges with the civil security, the planned work by SCHAPI and the FFC for the year 2016 will allow studying the scope of these new data, not only on their content but also on the communication that must accompany their implementation to other actors.

Furthermore, other key players are interested in this information : insurances and their group to qualify the importance of compensation to be provided during a flood, as well as the managers of networks (transport, energy, water, etc.). These organizations have started working in particular on this subject [9]. The media also are other parties interested in the visual approach and because these data are adapted to communicate to different audiences.

Thus, the work undertaken will aim to improve communication on these data for their understanding and for defining the specific broadcast framework for the proper use of each actor. The redesign of the Vigicrues ${ }^{\circledR}$ website, planned by 2018 , into a larger portal for flood vigilance in France and overseas, should help guide these early works.

\section{Conclusion}

Since 2011, several activities have been performed to implement a new reference dataset : the potential flooded areas. Tasks from pooling resources to collect and valorise observed data to others related to the operational production organisation have been conducted by the SCHAPI and the FFC. Today, these reference data can be generated at national level. Flooding forecasting is made possible thanks to the national database VIGInond, which allows storage and diffusion of flooded areas to ministerial services.

As a first step, dissemination to crisis managers is planned during the first semester of 2016, leading to their appropriation of this new information. For the second half of 2016, VIGInond will become operational, opening therefore the potential distribution of these data to other partners impacted by flood hazard.

Disseminating these data to the general public is a later target. Legal issues and preparation of documents explaining how ZIP must be used is a prerequisite.

Finally, crisis managers will be able to provide feedback about this information and express their needs about real time cartographic studies.

\section{References}

1. Gourley J. J., Erlingis J. M., Smith T. M., Ortega K. L., and Hong Y. (2010) Remote collection and analysis of witness reports on flash floods. J. Hydrol., 394, 53-62.

2. Le Bourhis J.-P. (2007). Du savoir cartographique au pouvoir bureaucratique. Les cartes des zones inondables dans la politique des risques (1970-2000). Genèses 3/2007, n $\mathbf{6 8}^{\circ}, 75$ 96.

3. J.-L. Souldadié, A. Escudier, D. Boilet, H. Doumenc, C. Brousse, B. Sabourin (2012) Prévision des inondations : bilan des expériences pilote, pré-requis et perspectives. Rapport $D G P R, \mathbf{5 5}, 21-25$.

4. H. Yésou, A. Escudier, S. Battiston, J.-Y. Dardillac, S. Clandillon, C. Uribe, M. Caspard, H. Giraud, J. Maxant, A. Durand, K. Fellah, M. Studer, C. Huber, L. Philippoteaux, P. de Fraipont, D. Fontannaz (2015) - Exploitation de l'imagerie Pléiades-THR en cartographie réactive suite à des catastrophes naturelles ayant affecté le territoire français en 2013. Revue Française de Photogrammétrie et de Télédétection, No 209.

5. Piotte O., Pasquet F., Chaléon C., Chambon D., Thomas L., Souldadié J.-L., Perherin C., Galiana C. (2016) Toward a collaborative management approach of high water marks data. Congrès SHF/AFEPTB - "Gestion des risques inondation : Méthodes et outils pour une approche partenariale ".

6. Pons F. (2012). Approche EXZECO-CARTINO pour la cartographie des inondations. 9èmes Journées Scientifiques et Techniques - Paris 3, 4 et 5 décembre 2012.

7. Valorge A., Billy P., Langumier J. (2014) Cartographie du risque d'inondation : réévaluation de la géomatique par rapport à l'hydraulique. Développement de processus automatiques de cartographie à l'occasion de la mise en oeuvre de la directive Inondation. Géomatique expert, no 98, 32-47.

8. Chaikin G. (1974). An algorithm for high speed curve generation. Computer Graphics and Image Processing 3, 346-349.

9. Moncoulon D. et Quantin A. (2013). Modélisation des événements extrêmes d'inondation en France métropolitaine. La Houille Blanche, no 1(2013), 22-26. 